\title{
Validation of a semi-quantitative food-frequency questionnaire used among 2-year-old Norwegian children
}

\author{
LF Andersen $^{1,2, *}$, B Lande ${ }^{1,3}, \mathrm{~K} \mathrm{Trygg}^{1}$ and $\mathrm{G} \mathrm{Hay}{ }^{1}$ \\ ${ }^{1}$ Institute for Nutrition Research, University of Oslo, Norway: ${ }^{2}$ Correspondence address: Division of Epidemiology, \\ 1300 S Second Street, Suite 300, Minneapolis, MN 55454, USA: ${ }^{3}$ Norwegian Directorate for Health and Social \\ Welfare, Department for Nutrition, Oslo, Norway
}

Submitted 29 September 2003: Accepted 16 February 2004

\begin{abstract}
Objectives: An adequate diet is of profound importance in infancy and early childhood. To ensure an optimal diet, knowledge about actual intake must be obtained. The aims of this study were to assess the validity of a semi-quantitative food-frequency questionnaire (SFFQ) applied in a large nation-wide survey among 2-year-old children and to examine the validity of the SFFQ in relation to different background parameters.

Design: The SFFQ was administered to the parents close to the child's second birthday, and one to two weeks later they started to weigh and record the child's diet for 7 days.

Subjects: One-hundred and eighty-seven families with a 2-year-old child completed both methods.

Results: There were no differences between the intakes of protein, saturated fatty acids, total carbohydrates and calcium estimated from the two methods. The average intake of all micronutrients, except for calcium, was overestimated by the SFFQ. Bland-Altman plots showed a systematic increase in difference between the two methods with increasing intake for most nutrients. Spearman correlation coefficients between methods for nutrient intakes ranged from 0.26 to 0.50 , the median correlation was 0.38 . The correlations increased when estimates were adjusted for energy intake, the median correlation being 0.52 . Differences in observed validity were found according to the number of siblings.

Conclusions: This study indicates that the SFFQ may be a valuable tool for measuring average intakes of energy, macronutrients and several food items among a 2-year-old population in Norway. The ability of the questionnaire to rank children according to intakes of nutrients and food items was rather low.
\end{abstract}

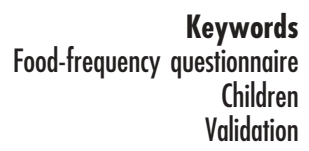

An adequate diet is of profound importance in infancy and early childhood. To ensure an optimal diet, knowledge about actual intake must be obtained. Such knowledge should be taken into account when recommendations are made, and is also important in assessments of regulations for food products intended for infants and children. Surveillance of dietary intake requires a reliable tool for obtaining information about food intake that is easy to distribute to a relatively large sample of individuals.

In 1999, a nation-wide sample of 3000 2-year-old Norwegian infants was invited to participate in a dietary survey. A total of 1727 families agreed to participate (participation rate 58\%). The overall aim of the survey was to provide detailed information on the current dietary habits among 2-year-old children in Norway, both at the group level and to rank individuals according to intake. The method selected for this survey was a semiquantitative food-frequency questionnaire (SFFQ), because it is considered the most suitable method for assessing dietary intake in large groups and because we have a lot of experience using this method among adolescents and adults ${ }^{1-5}$.

Validation studies of food-frequency questionnaires (FFQs) among pre-school children are scarce. In total, 10 validation studies of FFQs used among children $\leq 5$ years of age have been published between 1976 and $2002^{6,7}$. Eight of these studies have validated FFQs based on the Willett questionnaire ${ }^{7}$. Two of the 10 studies evaluated an FFQ used among 2-year-old children ${ }^{8,9}$. None of these validation studies has examined the effect of background parameters, such as parental education, being in day care or not, and number of siblings, on the validity of the FFQ.

In this paper we present the relative validity of food and nutrient intakes estimated by the SFFQ applied in the nation-wide survey among 2-year-old children in Norway. 
Furthermore, the validity of the SFFQ is presented in relation to different background parameters. Validity was assessed by comparing food and nutrient intakes from the SFFQ against intakes from 7-day weighed records.

\section{Materials and methods}

\section{Subjects and design}

The families included in this validation study were recruited from the prospective study 'Dietary intake and nutritional status among Norwegian infants - a prospective study from birth to the age 2 year' in Oslo. An invitation and an SFFQ were posted to 363 of the 364 families who had their child included in the prospective study at birth. The invitation was sent some weeks before the child's second birthday. Two hundred and seventyeight families returned completed questionnaires, and 187 of these kept weighed records for a total of 7 days (participation rate 51\%). The food recording started one to two weeks after the SFFQ was completed.

The study protocol was approved by the regional ethical committee, and informed parental consent was obtained.

\section{Semi-quantitative food-frequency questionnaire}

The 12-page, optical mark readable questionnaire was designed to describe dietary habits at 2 years of age. The selection of food items in the questionnaire was based on data from earlier dietary surveys among infants, general knowledge about dietary habits in this age group and experiences from two other nation-wide surveys among adolescents and adults ${ }^{1,5}$. The mother, father or other caregiver was invited to complete the questionnaire as close to the child's second birthday as possible. They were asked to describe habitual dietary intake at 2 years of age; because dietary intake can vary a lot at this age, the parents were asked to think of their child's diet over the past 14 days when filling in the questionnaire. The SFFQ included 39 questions: four about use of milk (including breast milk), 15 about use of 125 food items grouped together according to the Norwegian meal pattern, three about use of dietary supplements such as cod liver oil and multivitamin/mineral supplements, and 17 questions on other food habits, how parents were informed on child nutrition, highest educational level of mother and father, the work situation of the mother and allergy/asthma in the family.

The frequency alternatives varied from never/less than once per month to several times a day. A photographic booklet including 16 series of colour photographs with four differently sized portions ranging from small (A) to large (D) was used by the parents when reporting the amounts of food eaten. When no photograph was available for a food item, household units were used, e.g. slices, pieces and spoons.

Data on length and weight at birth were collected from the children's health card, and length and weight of the children at 2 years of age were measured by healthcare personnel at the regular 2-year check-up.

\section{Weighed record (reference method)}

The weighed food record covered seven consecutive days. The participants were provided with record notebooks and a digital scale that measured with a precision of $\pm 2 \mathrm{~g}$ to a maximum of $5000 \mathrm{~g}$. They were given thorough practical and written instructions on how to weigh and describe in detail the consumption of foods and beverages, and especially to measure and note all foods wasted and not eaten. If the child was breast-fed the parents were asked to report how often the child was given breast milk. In the instruction it was stressed that the purpose of the study was to measure the habitual food intake and that any temptations to change the diet to simplify the recording or make the diet healthier should be counteracted. About $75 \%$ of the children attended day care or had a nanny outside the home, and one of the employees in the day-care centre or the nanny was trained by a nutritionist to record the child's diet. The forms were coded by three nutritionists, who also were in contact with the participants during the recording period to answer questions and solve any problems that arose.

\section{Nutrient calculations}

The daily intakes of energy, nutrients and food items were computed by using a food database and software systems developed at the Institute for Nutrition Research, University of Oslo. The food database is based mainly on the official food composition table ${ }^{10}$, and is continuously supplemented with data on new food items and nutrients. Cod liver oil and vitamin/mineral supplements were included in the nutrient calculations.

\section{Statistical analyses}

Statistical analyses were performed by SPSS, version 11.0 (SPSS Inc., Chicago, IL, USA). As the nutrient intake and food intake data were not normally distributed, nonparametric statistical methods were chosen. The sample medians, 25th and 75th percentiles were computed for intakes of nutrients and food items from the two dietary assessment methods. Nutrient intakes are presented as absolute values and nutrient densities. For protein, fats, carbohydrate and sugar, nutrient density was calculated as the percentage of energy provided by that nutrient; for vitamins and minerals, nutrient density was presented as intake in $\mu \mathrm{g}$ or $\mathrm{mg}$ per MJ. The differences between methods were tested with Wilcoxon's signed rank test (paired data) and the Mann-Whitney $U$-test (unpaired data).

The agreement between methods was analysed as proposed by Bland and Altman ${ }^{11}$, using a plot of the differences between the two measurements against the average of the measurements. This analysis assesses agreement of the different dietary assessment methods in 
groups, which is defined as the difference between the two methods (relative bias). Furthermore, the analysis also assesses the agreement in individuals, defined as the limit of agreement (plus or minus two standard deviations ( $\pm 2 \mathrm{SD}$ ) of the bias).

The relationship between the two measurements is also presented by Spearman rank correlation coefficients. Ninety-five per cent confidence intervals (CIs) were calculated for the correlation coefficients ${ }^{12}$. Furthermore, the agreement on category level between the questionnaire and the records was examined by classification of absolute intakes of nutrients and nutrient density divided into quartiles.

Differences between the two methods according to background variables were assessed using a MannWhitney test for the differences between two groups, e.g. the differences between the dietary assessment methods in the group of parents with high education were compared with the differences found in the group of parents with low education. Equality between the correlations observed in two independent groups was tested using a method proposed by Kleinbaum et al. ${ }^{13}$.

\section{Results}

Table 1 shows the characteristics of the 187 children in the validation study. The children included in the validation study did not differ from the 2-year-old children included in the nation-wide study according to weight, length and gender. The mothers in the validation study had a higher level of education, but there was no difference between the mean age of mothers in the validation study and the mean age of mothers in the nation-wide study. Only 12 of the children included in the validation study were given breast milk.

\section{Nutrient intakes}

Table 2 presents the average intakes of energy and nutrients measured by the SFFQ and the food records as absolute intakes and as nutrient densities. The energy

Table 1 Characteristics of the infants included in the validation study $(n=187)$ and the nation-wide study among 2-year-old infants $(n=1727)$. Values are expressed as $n(\%)$ or median $\left(\mathrm{P}_{25}, \mathrm{P}_{75}\right)$

\begin{tabular}{lcc}
\hline & Validation study & \multicolumn{1}{c}{ Main study } \\
\hline Girls & $88(47)$ & $854(49)$ \\
Boys & $99(53)$ & $873(51)$ \\
Age (months) & $24.3(23.9,25.6)^{\star}$ & $24.2(23.8,25.9) \S$ \\
Weight $(\mathrm{kg})$ & $12.5(11.8,13.8) \dagger$ & $12.5(11.6,13.5) \emptyset$ \\
Height $(\mathrm{cm})$ & $89.0(86.5,91.0) \ddagger$ & $88.0(86.0,90.0) \|$ \\
\hline
\end{tabular}

$\mathrm{P}_{25}-25$ th percentile; $\mathrm{P}_{75}-75$ th percentile.

${ }^{*}$ Missing data for $n=39$.

† Missing data for $n=33$.

$\ddagger$ Missing data for $n=44$.

$\S$ Missing data for $n=307$

Missing data for $n=53$.

|| Missing data for $n=170$. intake was slightly overreported with the SFFQ as compared with the records (7\%). There was no significant difference between the absolute intakes of protein, carbohydrate, saturated fatty acids and calcium estimated from the two methods. Moreover, the SFFQ gave higher estimates of absolute intakes of other nutrients, except for fat, monounsaturated fatty acids and sugar, for which the records gave higher estimates. Similar results were found when nutrient densities were compared.

The Bland-Altman plots for most nutrients were similar to the plot of vitamin E intake (Fig. 1). There seemed to be a systematic increase in difference between the two methods with increasing intake. Moreover, the observed differences were both negative and positive, meaning that participants both under- and overreported nutrient intakes with the SFFQ compared with the weighed records. The limit of agreement, defined as the bias $\pm 2 \mathrm{SD}$ of the difference, was large for all nutrients.

Spearman correlation coefficients between pairwise measurements from the SFFQ and the food records ranged from 0.26 for fat, saturated fatty acids, monounsaturated fatty acids and calcium to 0.50 for intake of vitamin A. The median correlation coefficient for absolute nutrient intake was 0.38 (Table 3). The correlation coefficients generally increased when estimates were adjusted for energy intake. The median correlation coefficient for nutrient density was 0.52 .

Table 4 shows the ability of the SFFQ to classify individuals into the same quartile of intake estimated from the weighed record, and to misclassify into opposite quartiles. The proportion of subjects appearing in the same quartile varied from $29 \%$ for fat to $44 \%$ for vitamin A, with a median of 36\%. On average (median), 5\% were misclassified into extreme quartiles. When data were expressed as nutrient densities, the proportion of subjects appearing in the same quartile was on average (median) $42 \%$, and on average $4 \%$ of subjects were misclassified.

\section{Food intakes}

To obtain information about the ability of the questionnaire to cover the different foods in the diet, we also made comparisons at the food intake level for 15 food items (Table 5). There were no significant differences between the two methods regarding median intakes of vegetables, fruit juice, meat, fish and milk. For the rest of the food items shown in Table 5, higher intakes were reported in the questionnaire than in the records, except for cakes, soft drinks with sugar and chocolate/sweets. The Spearman correlation coefficients varied from 0.26 for potatoes to 0.69 for cod liver oil. The median correlation coefficient for food intake was 0.48 .

\section{Validity of the questionnaire related to different background parameters}

We investigated whether the observed validity of the SFFQ differed according to the parents' education level, whether 
Table 2 Daily intakes of energy and nutrients based on the SFFQ and WR (supplements are included) $(n=187)$. Values are expressed as median $\left(\mathrm{P}_{25}, \mathrm{P}_{75}\right)$

\begin{tabular}{|c|c|c|c|c|}
\hline \multirow[b]{2}{*}{ Nutrient } & \multicolumn{2}{|c|}{ Absolute intake† } & \multicolumn{2}{|c|}{ Nutrient density $\ddagger$} \\
\hline & SFFQ & WR & SFFQ & WR \\
\hline Energy & $4441(2708,5913)$ & $4161(3713,4535)^{\star}$ & & \\
\hline Protein & $34.2(22.0,45.8)$ & $32.9(28.4,37.3)$ & $13.3(12.2,14.5)$ & $13.5(12.3,15.1)$ \\
\hline Total fat & $36.4(26.1,53.5)$ & $36.5(31.6,41.0)^{\star}$ & $34.1(30.7,37.8)$ & $32.8(29.9,35.6)^{* *}$ \\
\hline SFA & $15.5(11.0,21.6)$ & $15.8(13.8,18.6)$ & $14.5(12.4,16.2)$ & $14.2(12.9,15.9)$ \\
\hline MUFA & $11.0(7.8,16.7)$ & $11.5(9.5,13.1)^{\star}$ & $10.6(9.2,11.6)$ & $10.2(9.1,11.1)^{\star}$ \\
\hline PUFA & $5.8(3.9,9.3)$ & $5.3(4.4,6.6)^{\star \star \star}$ & $5.4(4.2,6.9)$ & $4.8(3.9,5.8)^{\star \star \star}$ \\
\hline Total carbohydrates & $145.6(81.9,185.4)$ & $131.6(114.2,146.2)$ & $52.4(48.6,56.5)$ & $53.7(50.1,57.0)^{\star \star}$ \\
\hline Sugar§ & $24.4(13.9,40.1)$ & $32.7(23.5,44.0)^{\star * \star}$ & $10.6(7.2,13.5)$ & $13.3(9.8,17.6)^{\star \star \star}$ \\
\hline Fibre & $9.3(6.1,13.1)$ & $7.2(5.4,8.9)^{\star \star \star}$ & $2.1(1.7,2.5)$ & $1.7(1.4,2.1)^{\star \star \star}$ \\
\hline Vitamin A & $1130(772,1802)$ & $694(473,1027)^{\star \star \star}$ & $289(202,394)$ & $164(116,257)^{\star \star \star}$ \\
\hline Vitamin D & $6.5(4.0,9.3)$ & $3.9(1.6,7.3)^{\star \star \star}$ & $1.7(0.9,2.4)$ & $0.88(0.38,1.78)^{\star \star \star}$ \\
\hline Vitamin E & $6.3(4.4,9.3)$ & $4.7(2.9,7.2)^{\star \star \star}$ & $1.7(1.1,2.2)$ & $1.1(0.7,1.7)^{\star \star \star}$ \\
\hline Thiamine & $0.87(0.58,1.32)$ & $0.66(0.55,0.91)^{\star \star \star}$ & $0.19(0.16,0.28)$ & $0.16(0.14,0.21)^{\star \star \star}$ \\
\hline Riboflavin & $1.17(0.82,1.85)$ & $1.06(0.84,1.33)^{\star \star \star}$ & $0.28(0.23,0.37)$ & $0.26(0.21,0.31)^{\star * *}$ \\
\hline Vitamin C & $60(44,98)$ & $60(42,79)^{\star}$ & $16(11,21)$ & $14(10,19)^{\star}$ \\
\hline Calcium & $514(350,695)$ & $520(106,649)$ & $125(104,149)$ & $125(101,152)$ \\
\hline Iron & $4.9(3.2,6.8)$ & $4.5(3.6,5.2)^{\star \star \star}$ & $1.1(1.0,1.3)$ & $1.0(0.9,1.2)^{\star \star \star}$ \\
\hline
\end{tabular}

SFFQ - semi-quantitative food-frequency questionnaire; WR - weighed record; $P_{25}-25$ th percentile; $P_{75}-75$ th percentile; SFA - saturated fatty acids; MUFA - monounsaturated fatty acids; PUFA - polyunsaturated fatty acids.

†Absolute intake - energy was measured as $\mathrm{kJ}$; fats, protein and carbohydrates in g; vitamins $A$ and $D$ in $\mu \mathrm{g}$; the other vitamins and minerals in $\mathrm{mg}$.

$\ddagger$ Nutrient density - for protein, fats, carbohydrate and sugar, nutrient density is the percentage of total energy provided by that nutrient; for fibre, vitamins and minerals, nutrient density is intake in $\mu \mathrm{g}$ or $\mathrm{mg}$ per $\mathrm{MJ}$.

$\S$ Added sugar.

${ }^{\star}, P<0.05 ;{ }^{\star *}, P<0.01 ;{ }^{* \star *}, P<0.001$.

the child was attending day care or was staying at home with the parents, and the number of siblings.

Data from children with mothers having an education of 12 years or less $(n=61)$ and data from children with mothers having an education of more than 12 years $(n=121)$ were compared. The differences between absolute nutrient intakes from the weighed record and

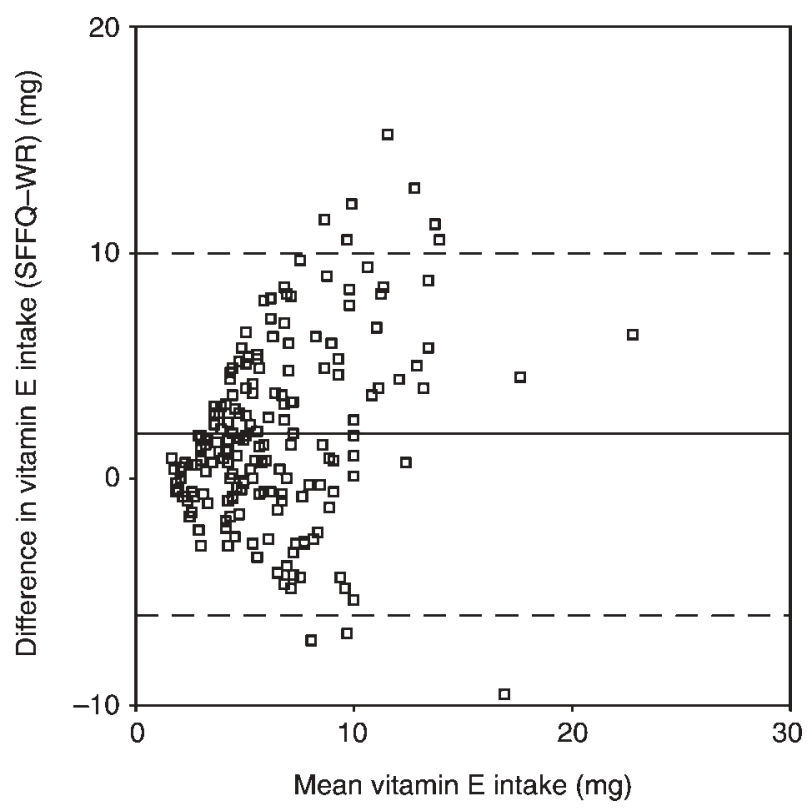

Fig. 1 Difference between vitamin $E$ intake estimated with the semi-quantitative food-frequency questionnaire (SFFQ) and the weighed record (WR) plotted against the mean vitamin $E$ intake from the two methods. Solid line - mean difference; dashed line - plus or minus two standard deviations $( \pm 2 S D)$ the SFFQ were not different between the two educational groups. Moreover, the correlation coefficients observed for nutrient intakes among the low-education group were not different from those observed for the high-education group, except for intake of added sugar.

Data from children who stayed at home during the day $(n=32)$ and children attending day care or who had a nanny $(n=140)$ were analysed separately. The differences in nutrient intakes from the weighed record and the SFFQ were not different between the two groups. Furthermore, the correlation coefficients observed for nutrient intakes among the children attending day care or who had a nanny were not different from those observed for the children staying at home.

When data from the children without siblings $(n=96)$ and the children with siblings $(n=91)$ were compared, the differences between nutrient intakes from the weighed record and the SFFQ did not differ between the two groups. However, the correlation coefficients for nutrient intakes observed for the group of children with siblings were in general higher than those observed among the children without siblings. Only the correlations for energy and macronutrients were significantly different.

\section{Discussion}

In the present study the relative validity of a semiquantitative food-frequency questionnaire used among 2 -year-old children was examined. This validation study is one of the largest validation studies among pre-school children done in a single age group. We are aware of only 
Table 3 Spearman's $r$ and 95\% Cl between intake of energy and nutrients based on the SFFQ and WR $(n=187)$

\begin{tabular}{|c|c|c|c|c|}
\hline \multirow[b]{2}{*}{ Nutrient } & \multicolumn{2}{|c|}{ Absolute intake $†$} & \multicolumn{2}{|c|}{ Nutrient density $\ddagger$} \\
\hline & Spearman's $r$ & $95 \% \mathrm{Cl}$ & Spearman's $r$ & $95 \% \mathrm{Cl}$ \\
\hline Energy & 0.31 & $0.18,0.47$ & & \\
\hline Protein & 0.27 & $0.13,0.42$ & 0.47 & $0.37,0.65$ \\
\hline Total fat & 0.26 & $0.12,0.41$ & 0.46 & $0.35,0.64$ \\
\hline SFA & 0.26 & $0.12,0.41$ & 0.51 & $0.42,0.71$ \\
\hline MUFA & 0.26 & $0.12,0.41$ & 0.50 & $0.40,0.69$ \\
\hline PUFA & 0.43 & $0.32,0.60$ & 0.46 & $0.35,0.64$ \\
\hline Total carbohydrates & 0.38 & $0.26,0.54$ & 0.48 & $0.38,0.67$ \\
\hline Sugar§ & 0.49 & $0.39,0.68$ & 0.53 & $0.45,0.73$ \\
\hline Fibre & 0.38 & $0.26,0.54$ & 0.53 & $0.45,0.73$ \\
\hline Vitamin A & 0.50 & $0.40,0.69$ & 0.66 & $0.65,0.94$ \\
\hline Vitamin D & 0.41 & $0.29,0.58$ & 0.53 & $0.45,0.73$ \\
\hline Vitamin E & 0.42 & $0.30,0.59$ & 0.58 & $0.52,0.81$ \\
\hline Thiamine & 0.44 & $0.33,0.62$ & 0.63 & $0.60,0.89$ \\
\hline Riboflavin & 0.35 & $0.22,0.51$ & 0.60 & $0.55,0.84$ \\
\hline Vitamin C & 0.39 & $0.27,0.56$ & 0.49 & $0.39,0.68$ \\
\hline Calcium & 0.26 & $0.12,0.41$ & 0.48 & $0.38,0.67$ \\
\hline Iron & 0.42 & $0.30,0.59$ & 0.66 & $0.65,0.94$ \\
\hline
\end{tabular}

$r$ - Spearman's rank correlation coefficient; CI - confidence interval; SFFQ - semi-quantitative food-frequency questionnaire; WR weighed record; SFA - saturated fatty acids; MUFA - monounsaturated fatty acids; PUFA - polyunsaturated fatty acids.

† Absolute intake - energy was measured as $\mathrm{kJ}$; fats, protein and carbohydrates in g; vitamins $A$ and $D$ in $\mu$; the other vitamins and minerals in $\mathrm{mg}$.

$\ddagger$ Nutrient density - for protein, fats, carbohydrate and sugar, nutrient density is the percentage of total energy provided by that nutrient; for fibre, vitamins and minerals, nutrient density is intake in $\mu \mathrm{g}$ or $\mathrm{mg}$ per MJ.

$\S$ Added sugar.

two other studies that have validated FFQs in the same age group $^{8,9}$. One of these studies was small, only 17 children aged 2-4 years were included ${ }^{9}$. In the study by Blum et ll. $^{8}, 129$ children of age $1-2$ years were included, and three repeated 24-hour recalls were used as the reference method.

Only a small overreporting of energy intake was observed for the SFFQ (7\%). The SFFQ gave higher median values than the weighed record for nine out of 16 nutrients. The largest differences were observed for the fat-soluble vitamins. This could be due to a higher intake of cod liver oil reported from the SFFQ than from the weighed record. For four out of 16 nutrients there were no differences between the methods and for three nutrients the record gave higher median values than the questionnaire. In a validation study among 64 12-month-old

Table 4 Classification of subjects by quartiles of calculated nutrient intake from the SFFQ and WR $(n=187)$

\begin{tabular}{|c|c|c|c|c|}
\hline \multirow[b]{2}{*}{ Nutrient } & \multicolumn{2}{|c|}{ Absolute intake $†$} & \multicolumn{2}{|c|}{ Nutrient density $\ddagger$} \\
\hline & $\begin{array}{l}\text { Correctly classified } \\
(\%)\end{array}$ & $\begin{array}{c}\text { Grossly misclassified } \\
(\%)\end{array}$ & $\begin{array}{c}\text { Correctly classified } \\
(\%)\end{array}$ & $\begin{array}{c}\text { Grossly misclassified } \\
\qquad(\%)\end{array}$ \\
\hline Energy & 31 & 6 & & \\
\hline Protein & 31 & 4 & 35 & 4 \\
\hline Total fat & 29 & 6 & 41 & 4 \\
\hline SFA & 35 & 6 & 42 & 4 \\
\hline MUFA & 36 & 10 & 46 & 3 \\
\hline PUFA & 39 & 4 & 36 & 6 \\
\hline Total carbohydrates & 37 & 6 & 42 & 4 \\
\hline Sugar§ & 36 & 3 & 40 & 2 \\
\hline Fibre & 37 & 5 & 37 & 4 \\
\hline Vitamin A & 44 & 4 & 45 & 1 \\
\hline Vitamin D & 41 & 4 & 42 & 4 \\
\hline Vitamin $\mathrm{E}$ & 39 & 5 & 42 & 2 \\
\hline Thiamine & 34 & 4 & 48 & 4 \\
\hline Riboflavin & 33 & 4 & 44 & 4 \\
\hline Vitamin C & 36 & 7 & 45 & 3 \\
\hline Calcium & 33 & 6 & 42 & 5 \\
\hline Iron & 34 & 3 & 47 & 2 \\
\hline
\end{tabular}

SFFQ - semi-quantitative food-frequency questionnaire; WR - weighed record; SFA - saturated fatty acids; MUFA - monounsaturated fatty acids; PUFA - polyunsaturated fatty acids.

†Absolute intake - energy was measured as $\mathrm{kJ}$; fats, protein and carbohydrates in g; vitamins $A$ and $D$ in $\mu \mathrm{g}$; the other vitamins and minerals in $\mathrm{mg}$

$\ddagger$ Nutrient density - for protein, fats, carbohydrate and sugar, nutrient density is the percentage of total energy provided by that nutrient; for fibre, vitamins and minerals, nutrient density is intake in $\mu \mathrm{g}$ or $\mathrm{mg}$ per MJ.

$\S$ Added sugar. 
Table 5 Daily intake of different food items $\left(\mathrm{g} \mathrm{day}^{-1}\right)$ based on the SFFQ and WR with values expressed as median $\left(\mathrm{P}_{25}, \mathrm{P}_{75}\right)$, and Spearman's $r$ and $95 \% \mathrm{Cl}(n=187)$

\begin{tabular}{|c|c|c|c|}
\hline Food & SFFQ & WR & $r(95 \% \mathrm{Cl})$ \\
\hline Bread & $62(42,103)$ & $57(43,78)^{\star \star \star}$ & $0.54(0.46,0.75)$ \\
\hline Cake & $11(6,19)$ & $20(10,35)^{\star \star \star}$ & $0.39(0.27,0.56)$ \\
\hline Potatoes & $17(9,27)$ & $12(5,22)^{\star \star}$ & $0.26(0.12,0.41)$ \\
\hline Vegetables & $18(9,30)$ & $16(7,30)$ & $0.43(0.32,0.60)$ \\
\hline Fruit, berries & $120(65,255)$ & $112(66,175)^{\star *}$ & $0.57(0.50,0.79)$ \\
\hline Fruit juice & $22(0,60)$ & $21(0,69)$ & $0.62(0.58,0.87)$ \\
\hline Meat & $31(18,46)$ & $33(21,48)$ & $0.40(0.28,0.57)$ \\
\hline Fish & $11(6,19)$ & $11(4,21)$ & $0.41(0.29,0.58)$ \\
\hline Cheese & $11(6,19)$ & $10(6,16)^{\star \star}$ & $0.52(0.43,0.72)$ \\
\hline Yoghurt & $50(25,98)$ & $45(13,87)^{\star \star}$ & $0.53(0.45,0.73)$ \\
\hline Milk & $202(109,294)$ & $220(114,314)$ & $0.48(0.38,0.67)$ \\
\hline Soft drinks† with sugar & $62(17,137)$ & $116(51,204)^{\star \star \star}$ & $0.53(0.45,0.73)$ \\
\hline Soft drinks without sugar & $0(0,0)$ & $0(0,36)^{\star \star}$ & $0.44(0.33,0.62)$ \\
\hline Chocolate, sweets & $3(1,5)$ & $4(1,8)^{\star \star \star}$ & $0.31(0.18,0.47)$ \\
\hline Cod liver oil & $0(0,2.5)$ & $0(0,1.4)^{\star *}$ & $0.69(0.70,0.99)$ \\
\hline
\end{tabular}

SFFQ - semi-quantitative food-frequency questionnaire; WR - weighed record; $\mathrm{P}_{25}-25$ th percentile; $\mathrm{P}_{75}-75$ th percentile; $r-$ Spearman's rank correlation coefficient; $\mathrm{Cl}$ - confidence interval. $\dagger$ Soft drinks is carbonated soft drinks and squash.

${ }^{\star}, P<0.05 ;{ }^{* \star}, P<0.01 ;{ }^{* \star *}, P<0.001$

Norwegian infants, an SFFQ similar to the one used in the present study was validated ${ }^{6}$. In that study the SFFQ gave higher median values for all nutrients except one. Several other validation studies of FFQs used among pre-school children have also shown that questionnaires overestimate nutrient intakes ${ }^{8,14,15}$. Blum et al. ${ }^{8}$ observed that their questionnaire overestimated 12 out of 20 nutrients and underestimated three (significance testing not shown). Treiber et $_{\text {al. }}{ }^{15}$ found among 3- to 5-year-old children that their questionnaire overestimated intake of 10 out of 11 nutrients, and this was similar to the observations in the same age group by Stein et al. ${ }^{14}$.

Bland-Altman plots indicate the scatter of individual results. The plots for all nutrients showed a wide scatter of differences between intake estimated with the SFFQ and with the weighed record at the individual level. The wide scattering of the differences showed clearly that some subjects under- or overreported their intake with the SFFQ more than others and that the tendency for under- or overreporting increased with intake. The same pattern was observed among 12-month-old infants ${ }^{6}$.

The correlations observed for absolute nutrient intakes in the present study were lower than what we have observed in validation studies of FFQs used among 12month-old infants, adults and adolescents ${ }^{1,3,4,6}$. In all of these studies the weighed record was used as the reference method. The correlations in the present study were also lower than those observed by Blum et al. ${ }^{8}$. However, the correlation coefficients for nutrient density values estimated from the two methods were much higher than seen for absolute nutrient intakes, and for 10 out of 16 nutrients the correlations were $>0.50$. The average correlation (median $r=0.52$ ) for nutrient density was similar to that observed among 12-month-old Norwegian infants (median $r=0.50)^{6}$. The agreement across quartiles between the two methods obtained in our study was on average (median) 36\%, which is similar to what we observed among 12-month-old infants $(38 \%)^{6}$. The agreement across quartiles increased when using nutrient density.

Only a few of the validation studies among pre-school children have analysed their FFQ according to food intake. The present study showed that the food items underreported were typical unhealthy foods like cake, soft drinks and sweets, while the overreported foods were more healthy foods like bread, fruit and potatoes. This pattern has been seen in validation studies before. The average correlation (median $r=0.48$ ) observed for food items in this study was lower than observed in the study among 12-month-old infants (median $r=0.62$ ). This could be expected because the diet is less diversified at 12 months of age, and therefore simpler to describe. Moreover, 12-month-old children are usually fed by the caregiver as opposed to the situation a year later, when most children feed themselves. It is important to remember that the correlations obtained from these different studies are not directly comparable because different food items are included in the analysis.

No other validation studies among pre-school children have examined the effect of parents' education, being in day care/having a nanny or not, and number of siblings on the validity of an FFQ. In the present study, the parents with more than one child seem to give more valid data in the SFFQ than the parents with only one child. No difference was observed for the SFFQ validity according to parents' education length or whether the child attended day care/had a nanny or not. We had expected that accuracy of parental report of their child's diet in the SFFQ would be reduced for children being away from home, owing to the limited ability of parents to know what their 
child eats in day care. However, these results indicate that even if the children are staying in day care/have a nanny the parents seem to be able to report the diet of their child.

\section{Methodological issues}

In a validation study the reference method used should be as accurate as possible. Nelson et al. ${ }^{16}$ have calculated the number of daily food records necessary to correctly classify $80 \%$ of toddlers into the extreme thirds of the distribution. They found that 7 days of weighed records for toddlers would suffice for satisfactory ranking of subjects according to intakes of macronutrients, calcium, iron, thiamine, riboflavin and vitamin $\mathrm{C}$.

Based on the average weight of the children in this study and data on energy requirements among 24-month-old children of $400 \mathrm{~kJ} \mathrm{~kg}^{-1} \mathrm{day}^{-1}$, the average energy intake should be about $5000 \mathrm{~kJ} \mathrm{day}^{-1}\left(12.5 \mathrm{~kg} \times 400 \mathrm{~kJ} \mathrm{~kg}^{-1}\right.$ day $\left.^{-1}\right)^{17}$. This calculated value for energy intake is somewhat higher than what we estimated from the weighed records, so it seems as if there has been some degree of underreporting with the weighed record (Table 2 ). Nine children had an energy intake from the weighed record below $3000 \mathrm{~kJ}$, indicating that their food intake might be underestimated. However, when calculating the association between energy and nutrient intakes estimated from the records and from the SFFQ, the correlation coefficients were similar with and without the nine infants included (data not shown).

\section{Sample representativeness}

The sample in the present study was a non-random sample in a certain area (Oslo) and not a random sample of 2-year-old children. The invited families were already part of another dietary study and the parents were probably more health-conscious and motivated than a random group of parents would be. We did not find any differences between height, weight and proportion of boys and girls in the validation sample compared with the sample in the nation-wide survey among 2-year-old children. However, the mothers in the validation study had higher educational level compared with the mothers in the nation-wide survey. The same result was observed in the validation study among 12-month-old infants ${ }^{6}$.

In summary, the present validation study indicates that the SFFQ may be a valuable tool for measuring average intakes of energy, macronutrients and several food items among a 2-year-old population in Norway. However, the capability of the questionnaire to rank children according to intakes of nutrients and food items was rather low, but increased when using nutrient density values instead of absolute intakes. Furthermore, we found that the validity of the SFFQ was not influenced by the length of parents' education or whether the child was attending day care or not.

\section{Acknowledgements}

The authors wish to thank Kirsti Kverndokk Bjerkan, Ellen-Margrethe Hovland and Kathrine C Haavardsholm for their help with collecting the dietary data. The project was supported by grants from the Norwegian Research Council.

\section{References}

1 Andersen LF, Nes M, Lillegaard IT, Sandstad B, Bjørneboe G-EAa, Drevon CA. Evaluation of a quantitative food frequency questionnaire used in a group of Norwegian adolescents. European Journal of Clinical Nutrition 1995; 49: 543-54.

2 Andersen LF, Solvoll S, Drevon CA. Very-long-chain $n-3$ fatty acids as biomarkers for intake of fish and $n-3$ fatty acid concentrates. American Journal of Clinical Nutrition 1996; 64: 305-11.

3 Andersen LF, Solvoll K, Johansson L, Salminen I, Aro A, Drevon CA. Evaluation of a food frequency questionnaire with weighed records, fatty acids, and alpha-tocopherol in adipose tissue and serum. American Journal of Epidemiology 1999; 150: 75-87.

4 Nes M, Frost Andersen L, Solvoll K, Sandstad B, Hustvedt BE, Lovo A, et al. Accuracy of a quantitative food frequency questionnaire applied in elderly Norwegian women. European Journal of Clinical Nutrition 1992; 46: 809-21.

5 Solvoll K, Lund-Larsen K, Søyland E, Sandstad B, Drevon CA. A quantitative food frequency questionnaire evaluated in a group of dermatologic outpatients. Scandinavian Journal of Nutrition 1993; 37: 150-5.

6 Andersen LF, Lande B, Arsky GH, Trygg K. Validation of a semi-quantitative food frequency questionnaire used among 12-months old Norwegian infants. European Journal of Clinical Nutrition 2003; 57: 881-8.

7 Serdula MK, Alexander MP, Scanlon KS, Bowman BA. What are preschool children eating? A review of dietary assessment. Annual Review of Nutrition 2001; 21: 476-98.

8 Blum RE, Wei EK, Rockett HR, Langeliers JD, Leppert J, Gardner JD, et al. Validation of a food frequency questionnaire in Native American and Caucasian children 1 to 5 years of age. Maternal and Child Health Journal 1999; 3: $167-73$.

9 Iannotti RJ, Zuckerman AE, Blyer EM, O'Brien RW, Finn J, Spillman DM. Comparison of dietary intake methods with young children. Psychological Reports 1994; 74: 883-9.

10 Rimestad AH, Løken EB, Nordbotten A. The Norwegian food composition table and calculation system used at the Institute for Nutrition Research. Norwegian Epidemiology 2000; 10: 107-10.

11 Bland JM, Altman DG. Statistical methods for assessing agreement between two methods of clinical measurement. Lancet 1986; 1: 307-10.

12 Altman DG. Relation between two continuous variables. In: Altman DG, ed. Practical Statistics for Medical Research, 1st ed. London: Chapman \& Hall, 1991; 277-324.

13 Kleinbaum DG, Kupper LL, Muller KE. The correlation coefficient and straight-line regression analysis. In: Kleinbaum DG, Kupper LL, Muller KE, eds. Applied Regression Analysis and Other Multivariable Methods, 2nd ed. Boston, MA: PWS-KENT Publishing Company, 1987; 80-95.

14 Stein AD, Shea S, Basch CE, Contento I, Zybert P. Consistency of the Willett semiquantitative food frequency questionnaire and 24-h dietary recalls in estimating nutrient intakes of preschool children. American Journal of Epidemiology 1992; 135: 667-77.

15 Treiber FA, Leonard SB, Frank G, Musante L, Davis H, Strong 
WB, et al. Dietary assessment instruments for preschool children: reliability of parental responses to the 24-h recall and a food frequency questionnaire. Journal of the American Dietetic Association 1990; 90: 814-20.

16 Nelson M, Black AE, Morris JA, Cole TJ. Between- and within-subject variation in nutrient intake from infancy to old age: estimating the number of days required to rank dietary intakes with desired precision. American Journal of Clinical Nutrition 1989; 50: 155-67.

17 Sandström B, Aro A, Becker W, Lyhne N, Pedersen JI, Torsdottir I. Nordic Nutrition Recommendations 1996. Copenhagen: Nordisk Forlaghus, 1996 [in Swedish]. 